\title{
PCM FOR BUILDING COOLING
}

\author{
Ravikumar M. ${ }^{1}$, Srinivasan P.S.S. ${ }^{2}$ \\ 'Department of Mechanical Engineering, B I T, Sathyamangalam, Erode, India \\ ${ }^{2} \mathrm{~K}$ S R College of Technology, Tiruchengode, Erode, India \\ Email: ${ }^{1}$ kumarmravi74@yahoo.co.in
}

\begin{abstract}
Due to climatic change, increasing thermal loads in buildings and rising living standards, comfort cooling in buildings is becoming increasingly important and the demand for comfort cooling is expanding very quickly around the world. Cool thermal storage systems have the potential to become one of the primary solutions to the electrical power imbalance between production and demand, but also shift cooling energy use to off-peak periods and avoid peak demand charges. Cool storage system using phase change materials can be used for peak load shifting if they are installed in the building. Phase change material $(\mathrm{PCM})$ are one of the latent heat materials having low temperature range and high energy density of melting solidification compared to the sensible heat storage. The tests on transient heat transmissions across different roof structures were conducted. It was found that when installing PCM in the withering course (WC-mixture of broken bricks and lime mortar) region nearly uniform roof bottom surface temperature was maintained.
\end{abstract}

Key words: Building roof, Energy storage, heat transmission, Latent heat storage(LHS), Natural Cooling, Phase Change Material (PCM), Withering Course (WC).

\section{INTRODUCTION}

As a demand for air conditioning increased greatly during the last decade, large demands of electric power and limited reserves of fossil fuels have led to a surge of interest with efficient energy application. Electrical energy consumption varies significantly during the day and night according to the demand by the industrial, commercial and residential activities. In hot and cold climate countries, the major part of the load variation is due to the air conditioning and space heating respectively. This variation leads to a differential pricing system for peak and off peak periods of energy use. Recent discussions on topics like global warming and heat waves have brought attention once again to energy efficient cooling systems utilizing renewable energy sources. Climate change has brought additional challenges for cooling systems designers. Significant economic benefit can be achieved by thermal energy storage for heating and cooling in residential and commercial buildings. Buildings that will have large mass will react slowly to changes in heating and cooling demands.

LHS in a phase change material (PCM) is very attractive because of its high storage density with small temperature swing. Thermal energy storage in the walls, ceiling and floor of the buildings may be enhanced by encapsulating or embedding suitable PCMs within these surfaces. They can either capture solar energy directly or thermal energy through natural convection. Increasing the thermal storage capacity of building can increase human comfort by decreasing the frequency of internal air temperature swings so that indoor air temperature is closer to the desired temperature for a longer period of time. Many phase change materials has been studied and tested for different practical uses by many scientists. This paper attempts to analyze the information about application of PCM in the building roofs for residential and commercial establishments.

\section{CLASSIFICATION AND PROPERTIES OF PCM}

In 1983, Abhat [1] gave the general classification of energy storage material in Figure.1 and also by Lane [2,3], Dinser and Rosen [4]. These papers gave the full detail like classification and characteristics of PCM. B.Zalba [5] listed the properties of different PCM's (Organic, Inorganic, Fatty acids) like density, specific heat, thermal conductivity and melting temperature. Some of the important properties required for $\mathrm{PCM}$ are

- High latent heat of fusion per unit mass, so that a lesser amount of material stores a given amount of energy.

- High specific heat that provides additional sensible heat storage effect and also avoid sub cooling.

- High thermal conductivity so that the temperature gradient required for charging the storage material is small

- High density, so that a smaller container volume holds the material 


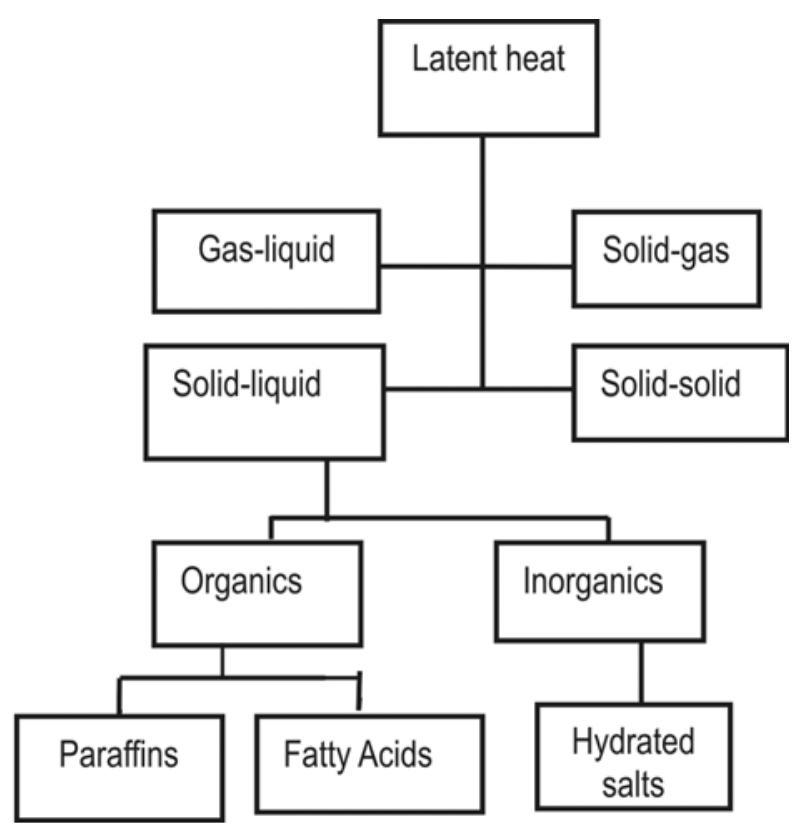

Fig. 1. Classification of PCM

1. A melting point in the desired operating temperature range.

I The phase change material should be nonpoisonous, non-flammable and non-explosive and corrosiveness to construction material

I No chemical decomposition, so that the (LHTS) system life is assured.

1 PCM should exhibit little or no super cooling during freezing

\section{APPLICATION OF PCM IN BUILDING}

There are three different ways to use PCMs for heating and cooling of buildings exist:

-PCMs in building walls;

-PCMs in building components other than walls i.e in ceilings and floors;

-PCMs in separate heat or cold stores.

In building applications, only PCMs that have a phase transition close to human comfort temperature $\left(20-28^{\circ} \mathrm{C}\right)$ can be used. Some Commercial PCMs have been also developed for building application.

Hawes and Feldman [6] have considered the means of PCM incorporation into the building by direct incorporation, immersion and encapsulation. Peippo et al. [7] considered a PCM impregnated plasterboard as a storage component in a lightweight passive $120 \mathrm{~m}^{2}$ solar house with good insulation and a large area of south facing glazing in Madison, Wisconsin . The house could save up to 3GJ in a year or $15 \%$ of the annual energy cost. Stetiu and Feustel [8] used a thermal building simulation program based on the finite difference approach to numerically evaluate the LHS performance of PCM wallboard in a building environment. Feustel and Stetiu [9] also investigated using double PCM-wallboard to further increase the storage capacity of a building so that the room temperatures could be kept closer to the upper comfort limits without using mechanical cooling. Neeper [10] has examined the thermal dynamics of a gypsum wallboard impregnated by fatty acids and paraffin waxes as PCMs that are subjected to the diurnal variation of room temperature but are not directly illuminated by the sun. Athienitis et al. [11] conducted an extensive experimental and one dimensional nonlinear numerical simulation study in a full scale outdoor test room with PCM gypsum board as inside wall lining. Lee et al. [12] have studied and presented the results of macro-scale tests that compare the thermal storage performance of ordinary concrete blocks with those that have been impregnated with two types of PCMs, BS and commercial paraffin. Hawes et al. [13] presented the thermal performance of PCM's (BS, dodecanol, paraffin, and tetradecanol) in different types of concrete blocks. Hadjieva et al. [14] have applied the same impregnation technique for concrete but with sodium thiosulphate penta hydrate (Na2S2O3.5H2O) as a PCM. A major development in this area is to develop a PCM which will maintain good heat storage during the day and heat loss to the environment during night time.

\section{PROBLEM FORMULATION}

Three roof structures are taken for studies are as follows:

Roof-1(RCC) : simple RCC roof (150mm thick);

Roof-2(WC : RCC roof (150mm thick) covered with withering courseWC ( $75 \mathrm{~mm}$ thick);

Roof -3 (PCM) : RCC roof (150mm thick) covered with WC $(75 \mathrm{~mm}$ thick) having 0

\section{A. Assumptions Made}

To study the system the following assumptions are made:

i) The temperature variation is two dimensional (across width and depth directions only);

ii) The ambient temperature $T_{\text {ma }}$ and solar heat flux $q$. are the functions of time over the day;

iii) The material properties are constant;

iv) Inside and outside heat transfer coefficients are constant; 
v) Radiation heat exchange within the room is neglected;

Due to similar symmetry of all these structures, width of all roofs was taken equally $(150 \mathrm{~mm})$ for the investigation. Boundary conditions were same for all types of roof.

\section{B. Boundary Conditions}

For right and Left

Bottom surface Convection, hi $=10 \mathrm{w} / \mathrm{m}^{2} \mathrm{k}, \mathrm{T}=25^{\circ} \mathrm{C}$ Top surface Convection, ho $=10 \mathrm{w} / \mathrm{m}^{2} \mathrm{k}, \mathrm{T}=$ hourly Values,Solar radiation flux, $\mathrm{q}=$ hourly values

\section{Thermo physical Properties of PCM}

Table 1. Thermo physical properties

\begin{tabular}{|c|c|c|c|}
\hline Material & $\begin{array}{r}\text { Density } \\
\left(\mathrm{Kg} / \mathrm{m}^{3}\right)\end{array}$ & $\begin{array}{r}\text { Thermal } \\
\text { Conductivity } \\
(\mathrm{W} / \mathrm{mK})\end{array}$ & $\begin{array}{l}\text { Specific } \\
\text { Heat } \\
(\mathrm{J} / \mathrm{Kg} \mathrm{K})\end{array}$ \\
\hline Concrete & 2300 & 1.279 & 1130 \\
\hline Withering & 1300 & 0.25 & 800 \\
course & $941^{*}$ & $0.172^{*}$ & $2.35^{*}$ \\
\hline $\begin{array}{c}\text { Phase } \\
\text { Change } \\
\text { Material } \\
\text { (PCM) }\end{array}$ & \multicolumn{2}{|c|}{ Latent heat } & 172 \\
\cline { 2 - 4 } & \multicolumn{2}{|c|}{} \\
\hline
\end{tabular}

*indicates for both solid and liquid state.

Solar insulation and weather data of Coimbatore city, Tamilnadu, India during June was used. $T_{\text {wata }}$ was found out by using the formula $T_{s=}=T_{a x p}+\left(a ́ q_{s} / h_{0}\right)$. The graph between the Time vs $T_{\text {mon }}$ and Time vs. $T_{\text {sutu }}$ was plotted as shown in the Figure.2

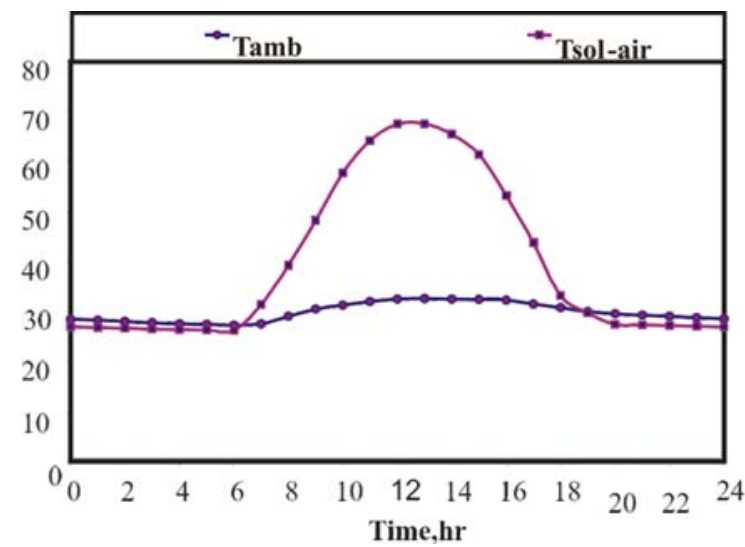

Fig. 2. Solar Radiation Data for Coimbatore during June 2006
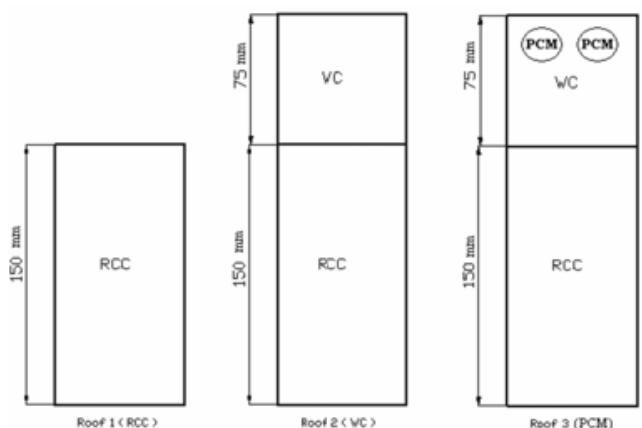

Fig. 3 Roof Structures

\section{Solution Methodology}

Three different roof structures are considered for the study as shown in the Figure.3. Roof structures were modeled and solved using thermal module of Ansys finite element analysis software. The roof was maintained at uniform temperature of $25^{\circ} \mathrm{C}$ to start the solution for the transient thermal analysis. The effect of this initial condition on the end results are avoided by repeating the solution for several days till the temperature distributions at the end of two consecutive days are equal. About 5 daysx 24 hours was found to be sufficient for attaining the solution. The 5 " day results are presented and discussed.

\section{RESULTS AND DISCUSSION}

The thickness of all the three roof structures are different, so the distance is normalized $\left(Y^{*}=Y / Y\right.$ max $)$ with $Y=0, Y^{*}=0$ referring to the bottom of the roof and $Y=Y \max$ and $Y^{*}=1.0$ referring the top surface of the roof.

\section{A. Temperature Distribution Across The Roof Structure}

There is no solar radiation on the building surface from $\hat{0}=0 \mathrm{hr}$ to $\hat{0}=6 \mathrm{hr}$. But the heat accumulated during the previous day travels on both the sides of the roof from the middle structure

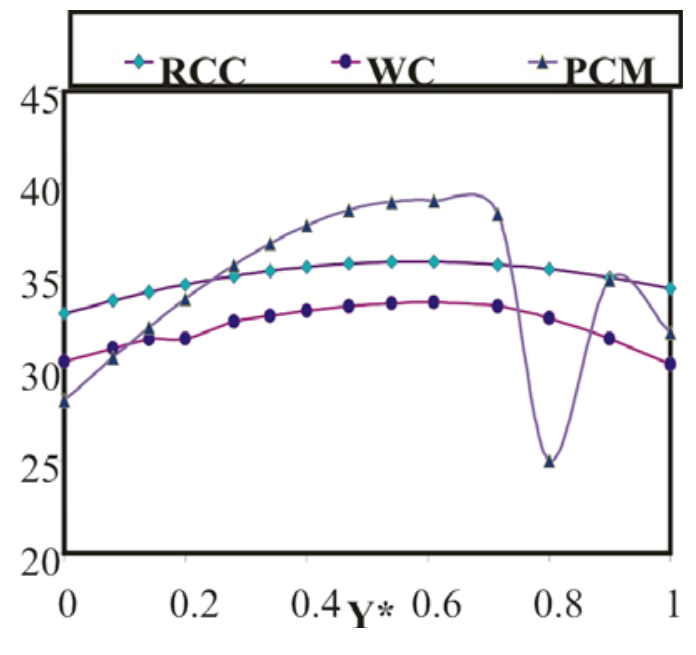

(i) $\hat{0}=0 \mathrm{hr}$ 


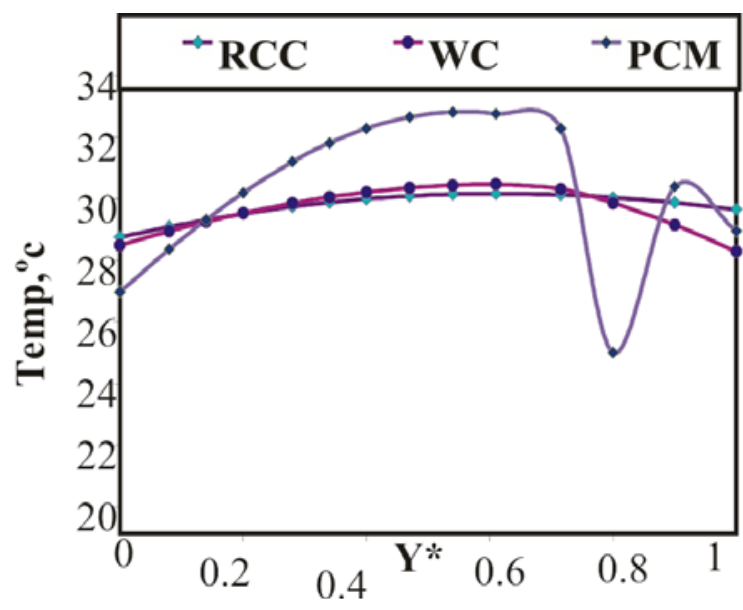

(ii) $\hat{o}=6 \mathrm{hr}$

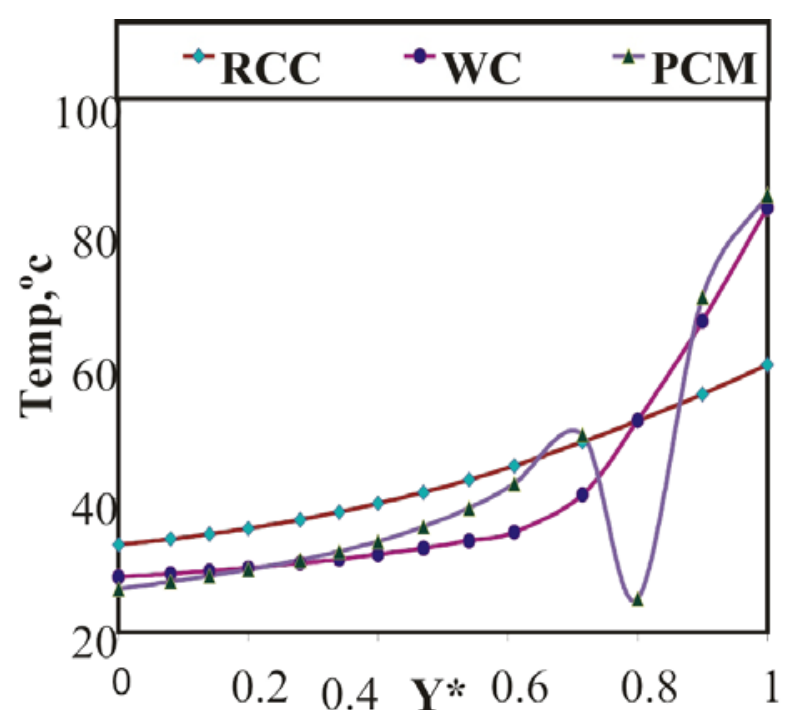

( iii) ô =12 hr

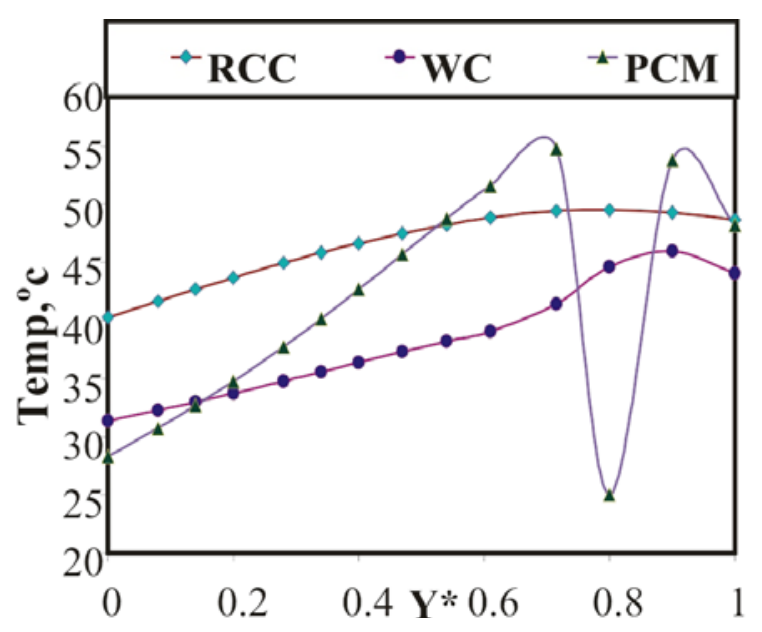

( iv) $0 \hat{=} 18 \mathrm{hr}$

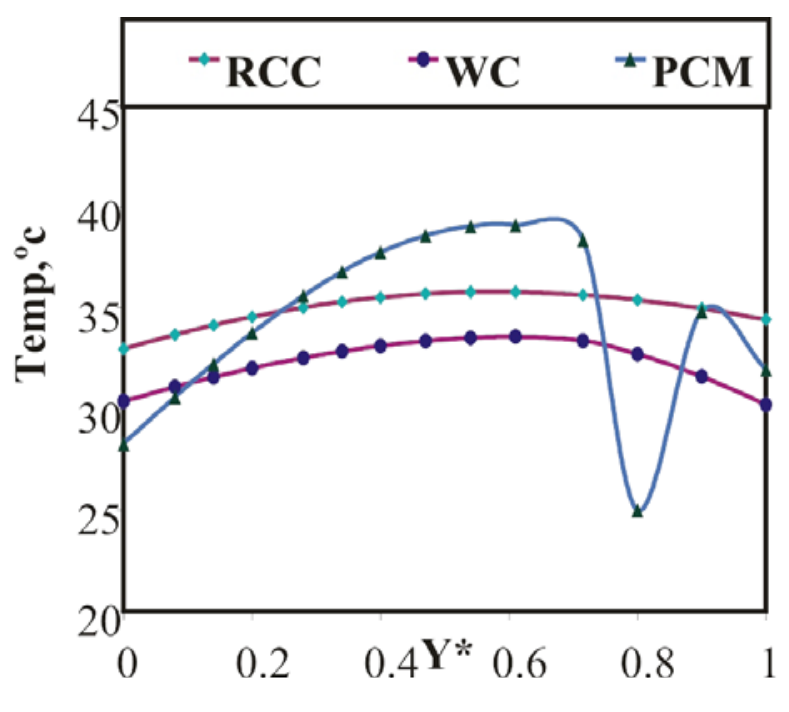

( v) $\hat{o}=24 \mathrm{hr}$

Fig. 4 ( i- v ). Temperature distribution across roof structure

The temperature distribution inside the roof was analyzed by using the Finite element analysis software ANSYS 10.The parameters required for the analyses are given below.

The temperatures at the top and bottom surfaces are lower compared to the temperature inside the roof. The average temperature for the concrete structure is the highest among all the other types of roofs as the thermal conductivity of RCC is more compared to the WC, WC with PCM. As the thermal conductivity of RCC is higher, more heat will be stored during the previous day. The thermal conductivity of WC with PCM is lowest compared to WC and RCC. The curve for Roof 3 falls below the other curves because PCM absorbs maximum heat energy passing through that roof. It brings down the temperature to the room temperature, where the PCM is located.

At $\hat{0}=6 \mathrm{hr}$ to $\hat{0}=12 \mathrm{hr}$, as the solar radiation falling on the surface increases, the heat transfer characteristics varying from the previous time period. As the thermal conductivity of the RCC is highest, whatever the heat enters all the heat will be transferred to the bottom so the curve is linear and average. The curve for the Roof 2 is also similar to the Roof 1 curve but slightly falls below the Roof 1 curve at the bottom and peak at the top. The curve for the Roof 3 reaches the least value at the bottom and it reaches the peak value in the top layer. At ô $=12 \mathrm{hr}$ to ô $=18 \mathrm{hr}$, the solar radiation falling on the roof decreases but the heat that has already entered travels inside the roof. The mid plane temperature values are higher than the ô $=12 \mathrm{hr}$.As the heat flux during this $\hat{0}=18 \mathrm{hr}$ is very small value, so the convection at the roof top dominates during this period. Compared to the Roof 1 , Roof 3 has reduced the temperature at the bottom of the roof by $12^{\circ}$. 
During ô $=18 \mathrm{hr}$ to ô $=24 \mathrm{hr}$, there is no solar radiation entering to the roof. So the temperature at the top and bottom of the roof is nearly at the same temperature. For the Roof 3 , temperature reaches peak value at the middle and in the WC region where PCM is located temperature falls suddenly to room temperature as the PCM absorbs all the heat passing through the roof. And it reaches almost least value at the bottom as the PCM installed region acts as thermal energy storage.

\section{B. Temperature Distribution At Roof Top Surface}

The variation of top surface temperature throughout the day was shown in the Figure.5. During $\hat{o}=0 \mathrm{hr}$ to $\hat{0}=6 \mathrm{hr}$ and $\hat{o}=18 \mathrm{hr}$ to $\hat{o}=24 \mathrm{hr}$ the top surface temperature reaches the low values. The temperature for the Roof 2 attains the lowest value and Roof 3 attains the highest value, because in the absence of solar radiation, the PCM has stored heat energy during the previous day releases the energy to the top surface. During ô $=6 \mathrm{hr}$ to ô $=18 \mathrm{hr}$ the top surface temperature for all the roofs increases initially and drops later.

The least value is observed for the Roof 1 structure and highest value for the Roof 3 structure. This is because Roof 2 and Roof 3 structure offers more resistance for the heat flow than the Roof 1 structure, makes the top surface temperature to go high for these two structures.

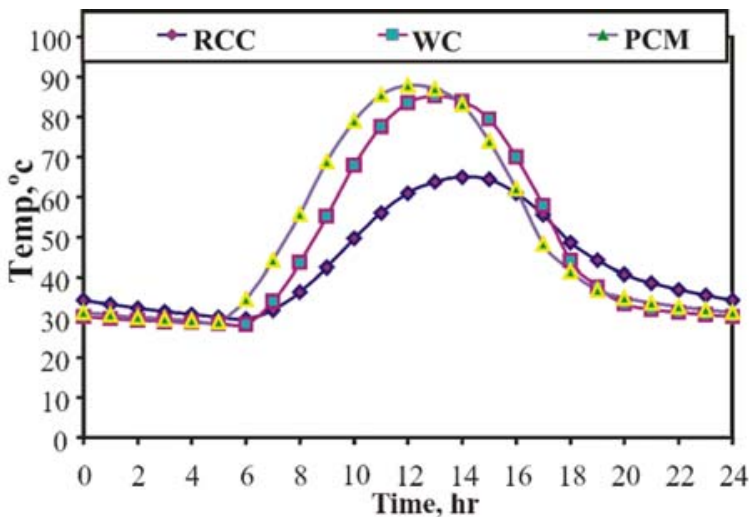

Fig. 5. Roof top surface temperature

\section{Temperature Distribution at Roof Bottom Surface}

The net heat entering in to the room is mainly determined by the bottom surface temperature. The bottom surface temperature for three different roof structures are plotted for different time period during the day along with the room temperature $(\mathrm{Tr})$ is shown in the Figure 6 . In the case of Roof 1 , it has good thermal conductivity, so the heat travels freely into the room and the room temperature is remarkably high value. The Roof 2 structure offers some resistance so the bottom temperature drops significantly. For the Roof 3 structure, as the thermal conductivity of PCM is very low it offers high resistance for heat flow, so the bottom temperature is nearly maintained constant.

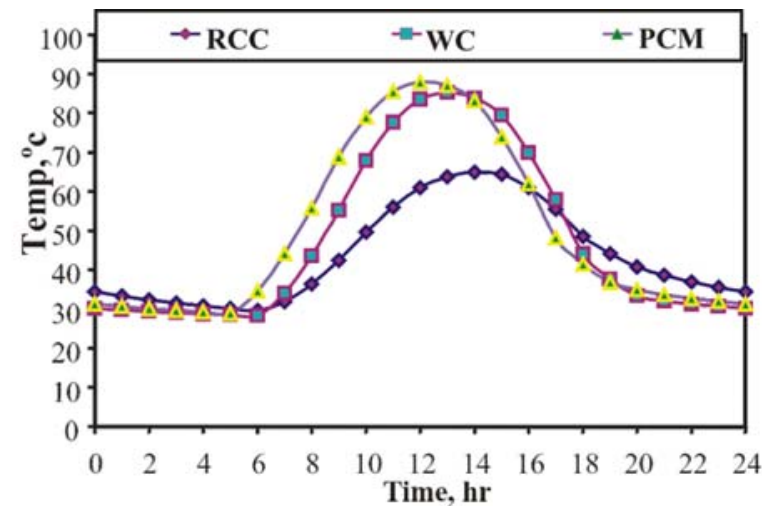

Fig. 6. Roof bottom surface temperature

D. Heat Energy Entering Into The Room

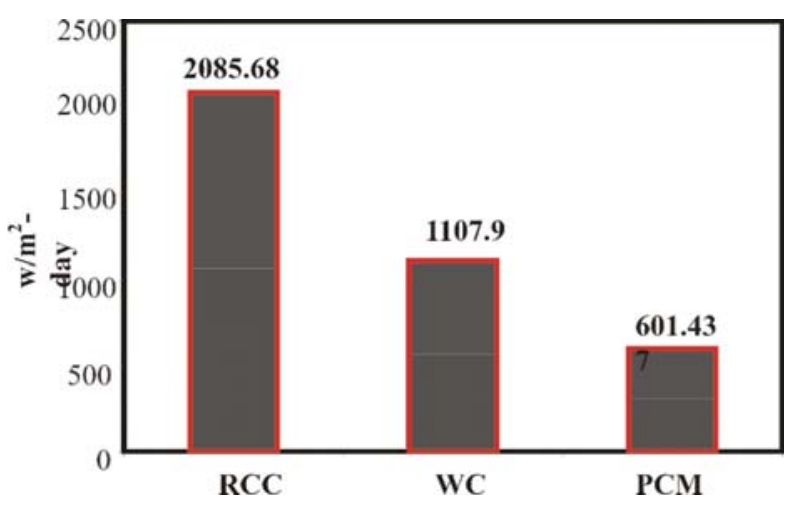

Fig. 7. Heat Flux Entering the room

From the Figure.7 it clearly states that Roof 3 is better than the Roof 2 and Roof 1 . If the roof is installed with PCM it can reduce the heat entering the room about more than two-third than the RCC laid roof. When compared with the Roof 1 , the Roof 2 and Roof 3 reduces the heat transfer by $46.88 \%$ and $71.16 \%$.As compared to Roof 2 with Roof 3 , reduction in net heat transfer was found to be $45.71 \%$. The reduction in heat transfer is directly proportional to the corresponding reduction in the electrical energy consumption for to maintain the room at $25^{\circ} \mathrm{C}$.

\section{CONCLUSION}

By installing phase change material in the building roof structure the effect of variation was studied. It was observed that maximum quantity of heat enters in to the room with RCC laid roof, because the thermal conductivity of RCC is maximum. In Roof 2 and Roof 3 the heat entering the room was reduced by $46.88 \%$ and $71.16 \%$. As the PCM is having low thermal conductivity, it offers the resistance for the heat flow and heat transfer was reduced by $45.71 \%$ compared to the Roof 3 . The most suitable material can be found out by repeating the test with various combinations 
of PCM. Optimization of PCM for building, the effects of thermo physical properties of PCM, installation methodology, location of PCM are the scope for future work.

\section{NOMENCLATURE}

$\mathrm{T}_{\text {sol }}$ Sol temperature

$\mathrm{T}_{\text {amb }}$ Ambient temperature

á = absorption coefficient

$\mathrm{q}_{\mathrm{s}}=$ heat flux in $\mathrm{w} / \mathrm{m}^{2}$

$h_{0}$ = room outside heat transfer coefficient

$h_{i}=$ room inside heat transfer coefficient

$T_{R}$ = room temperature in degree

\section{ACKNOWLEDGEMENT}

The authors are grateful to the management Of BIT for providing the necessary facilities and Prof Sakthivel for his encouragement during the study.

\section{REFERENCES}

[1] Abhat.A.1983."Low temperature latent heat thermal energy storage, Heat storage materials", solar energy; 30:313-32.

[2] G.A.Lane.1986."Solar heat storage: Latent heat material", vol II. Technology, CRS Press, Boca Raton, FL,

[3] G.A.Lane.1983."Solar heat storage:Latent heat material", vol I. Background and scientific principles, CRC press, Florida.

[4] I.Dincer, M.A.Rosen.2002."Thermal energy storage, systems and applications", John Wiley and sons, chickaester (England).

[5] Belen zalba, Jose M.Marin, Lusia Feabeza, Harald Mehling.2003. "Review on thermal energy storage with phase change materials, heat transfer analysis and application", Applied thermal engg 23, 251-283.

[6] Hawes DW, Feldman D.1992. "Absorption of phase change materials in concrete". Solar Energy Material and Solar Cells; 27:91-101.
[7] Peippo K, Kauranen P, Lund PD. 1991."A multicomponent PCM wall optimized for passive solar heating".Energy Building;17:259-70

[8] Feustel HE, Stetiu C. 1997."Thermal performance of phase change wallboard for Insert a passport size photograph in *. jpg format of the first author residential cooling application". Lawrence Berkeley National laboratory, Report LBL-38320.

[9] Feustel HE, Stetiu C. 1997. "Thermal performance of phase change wallboard for residential cooling application". Lawrence Berkeley National laboratory, ReportLBL-38320.

[10] Neeper D. 2000."Thermal dynamics of wall board with latent heat storage".Solar Energy;68:393-403.

[11] Athienitis AK, Liu C, Hawes D, Banu D, Feldman D. 1997. "Investigation of the thermal performance of a passive solar test-room with wall latent heat storage". Building Environment; 32:405-10.

[12] Lee T, Hawes DW, Banu D, Feldman D. 2000."Control aspects of latent heat storage and recovery in concrete". Solar Energy Material and Solar Cells; 62:217-37.

[13] Hawes DW, Banu D, Feldman D. 1990. "Latent heat storage in concrete II". Solar Energy Materials; 21:61-80.

[14] Hadjieva M, Stoykov R, Filipova T. 2000. "Composite salt-hydrate concrete system for building energy storage". Renewable Energy; 19:11-5.

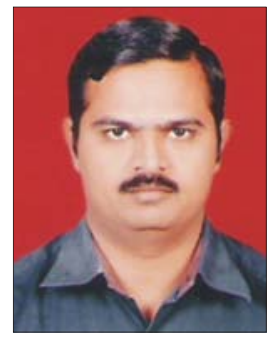

Mr. M.Ravikumar is a graduate from Coimbatore Institute of Technology in Mechanical Engineering and a Postgraduate from the Regional Engineering College, Trichy in the field of Energy Engineering. He has published papers in International and National journals. 